\title{
DURAL ARTERIOVENOUS MALFORMATIONS - CASE REPORT AND REVIEW OF THE LITERATURE
}

\author{
Daniela Rosu
}

National Institute of Neurology and Neurovascular Diseases, Bucharest

\begin{abstract}
The gold standard in dural arteriovenous fistulas (DAVF) evaluation is complete angiography. Treatment options include: conservative management, open surgery, endovascular therapy, stereotactic radiosurgery or multimodality therapy. The goal of microsurgical intervention is DAVF obliteration or selective CVD disconnection. We present a 59 years old male who was brought to the Emergency Department of the National Institute of Neurology and Neurovascular Diseases in a comatose state (GCS- $5 p$ ).
\end{abstract}

Keywords: arteriovenous malformation, angiography, management

\begin{abstract}
Abbreviations:
$\mathrm{CBF}$ - cerebral blood flow; $\quad$ DAVF - dural arteriovenous fistula;

AVM - arteriovenous malformation; 123 IMP - 123I-iodoamphetamine;

CVD - cerebral venous drainage; $\quad \mathrm{ICH}$ - intracerebral hemorrhage.
\end{abstract}

\section{DURAL ARTERIOVENOUS FISTULAS (DAVF)}

\section{Introduction}

Dural arteriovenous fistulas (DAVF) are lesions which consists of abnormal arteriovenous shunts within the dura mater. They are rare lesions, accounting for $10-15 \%$ of all intracranial AVMs. (39)

The mean age at presentation is between the sixth and seventh decade of life. $(2,35)$

Many reports suggest that the vast majority of patients who present with intracranial hemorrhage from a DAVF are males. (11)

These lesions are considered to be acquired, although it has been suggested that in some cases the DAVF may be congenital. (31) Fibromuscular dysplasia, Ehlers-Danlos syndrome and neurofibromatosis type I have been associated with DAVF. $(3,36)$

Iatrogenic DAVF appears most commonly secondary to intracranial surgery. There are 14 cases of iatrogenic DAVF described in the literature which developed after ventriculostomy, burr hole, craniotomy, or craniectomy. (37)

Dural arteriovenous fistulas adjacent to the craniocervical region most often present with progressive myelopathy related to spinal cord ischemia/ venous hypertension $(9,30)$ or, in rare cases, with with a brainstem stroke. (28)

They are ussualy located within or near the wall of a dural venous sinus. The nidus is contained within the dural leaflets, with the arterial supply ussualy deriving from dural arteries and less frequently from the osseous branches. Venous drainage occurs via a venous dural sinus, retrogradely through leptomeningeal veins. (34)

In an effort to assess the best option treatment, several classifications and grading systems have been proposed. $(6,9)$

The most commonly used are those of Borden and collegues and Cognard and collegues. $(6,9)$ 


\section{Borden Classification}

Type I

- drainage into a meningeal vein, spinal epidural veins or into a dural venous sinus;

- normal anterograde flow in both the draining veins and other veins draining into the system;

- equivalent to Cognard type I and IIa.

Type II

- drainage into a meningeal vein, spinal epidural veins or into a dural venous sinus;

- retrograde flow into the normal subarachnoid veins;

- equivalent to Cognard type IIb and IIa+b.

Type III

- direct drainage into subarachnoid veins or into an isolated segment of venous sinus (which results - from thrombosis on either side of the dural sinus segment);

- equivalent to Cognard type III, IV and V.

\section{Cognard classification}

Type $I$ - confined to sinus wall, typically after thrombosis.

\section{Type II}

IIa - confined to sinus with reflux (retrograde) into sinus but not cortical veins;

$\mathrm{IIb}$ - drains into sinus with reflux (retrograde) into cortical veins (10-20\% haemorrhage);

Type III - drains direct into cortical veins (not into sinus) drainage ( $40 \%$ haemorrhage);

Type $I V$ - drains direct into cortical veins (not into sinus) drainage with venous ectasia $(65 \%$ haemorrhage);

Type $V$ - spinal perimedullary venous drainage, associated with progressive myelopathy.

Hemorrhage is the most devastating presentation. The overall risk of hemorrhage for patients with DAVF is $1,6 \%$ per year. (8)

Bleeding may be intraventricular, intraparenchimal, subarachnoid or subdural and may be distant from the DAVF nidus.(5) The most common location for DAVFs presenting with hemorrhage is tentorial. (11)

Non hemorrhagic neurological presentation is secondary to congestive ischemia (global - dementia or focal neurological deficits - motor weakness, aphasia, cerebellar signs, progressive mielopathy) (42) or to venous hypertension (hydrocephalus or pseudotumor like syndrome). (15)

DAVFs may present incidentally or with symptoms related to the location and pattern of venous drainage. (22) Pulsatile tinnitus is the most common presenting symptom, most often seen with
DAVF at the transverse-sigmoid jonction. Headache is a common symptom. (39) Other symptoms related to DAVF are: proptosis, conjunctival injection, chemosis, ophtalmoplegia, visual loss, glaucoma, papilledema, facial pain (34), progressive dementia (23) or brainstem disfuction. (26)

The gold standard in DAVF evaluation is complete angiography (with selective internal and external injections).

MRI scans helps in determining intraparenchimal pathology such as dilated veins or edema. (27)

CT scan is most useful in the acute phase to assess for hemorrhage. (39)

Positron emission tomography measurements ( $\mathrm{CBF}$ and $\mathrm{O}_{2}$ extraction fraction) can show hemodynamic impairment, before and after the treatment. (24)

123I - IMP single photon emission computed tomography (SPECT) can also measure the cerebral hemodynamics in patients with DAVFs. The reduction of $\mathrm{rCBF}$ strongly correlates with the severity of venous congestive encephalopathy. (25)

The treatment options depend on previous hemorrhage, neurologic deficit or angiographic risk factors (the presence of leptomeningeal drainage). (39) Treatment options include: conservative management, open surgery, endovascular therapy, stereotactic radiosurgery or multimodality therapy. Endovascular therapy consists of transarterial or transvenous endovascular delivery of embolic agents (cyanoacrylate, ethyl alcohol, coils, and particles) or selective CVD disconnection. Transarterial glue embolisation is highly effective for Borden type III DAVFs with CVD, but has limitations for Borden type I and II DAVFs with diffuse shunts. The benefits of glue embolisation, compared to onyx embolisation, are high thrombogenicity, and relatively low risk of cranial nerve palsies and of excessive migration into the draining veins of high flow fistulas. (32)

The goal of microsurgical intervention is DAVF obliteration or selective CVD disconnection. (43)

Houdart et al had indicated that surgical treatment should be applied when space occupying effect of intracranial hematoma exists due to DAVF rupture. (21) Selective surgical interruption of the draining bridging vein is the treatment of choice in petrosal vein-draining and medulla bridging veindraining DAVFs that drain directly into the leptomeningeal vein. $(7,17,40)$

Selective CVD disconnection via surgical or endovascular has become the treatment of choice, due to documentation of a comparable efficacy to DAVF obliteration with significantly lower periprocedural risks. $(10,14,16,20,33)$ 
With the advent of newer embolic agents (Onyx, Covidien), endovascular procedures have become safe and effective, with onyx becoming the treatment of choice for DAVFs (32) The first therapeutic attempt for most DAVFs is via an endovascular approach, with microsurgery reserved for patients with persistent CVD following maximal endovascular therapy. (11) Successful treatment requires occlusion of the venous recipient and transvenous embolization has generally been favored in the past for intracranial DAVFs. (1)

In select DAVFs in which endovascular therapy carries considerable procedural risk (such as anterior fossa lesions with ethmoidal feeders originating from the ophthalmic artery), surgical intervention is the treatment of choice. (43)

The natural history of DAVFs depends greatly on the presence or absence of CVD. Dural AVFs without CVD have a benign natural history. Patients with Borden Type I DAVFs have a low risk of suffering an $\mathrm{ICH}$ and developing non hemorrhagic neurological deficits. (35)

Dural AVFs with CVD present a poor natural history. (13)

Patients who harbour dural AVFs with ICH or non hemorrhagic neurologic deficits, have a significant risk of future neurological events (12) and immediate treatment is necessary for all DAVFs with CVD (38).

Among aggressive DAVFs, the most challenging is the treatment of DAVFs in the transverse and sigmoid sinuses (lateral sinus) and in the confluence of sinuses. (30) Extremely high flow DAVF without sinus occlusion and CVD is best treated by transarterial embolization combined with transvenous occlusion, followed by resection of the diseased section of the sinus or surgical isolation of the segment and irradiation. Localized DAVF with exclusive CVD is best treated by transarterial embolization combined with surgical disconnection of CVD. DAVF with bifocal or diffuse sinus occlusion and CVD is best treated by transarterial embolization with or without complementary surgical isolation or resection of the lesion. Combining endovascular and neurosurgical treatments of highrisk dural arteriovenous fistulas in the lateral sinus and the confluence of the sinuses. (16)

Stereotactic radiosurgery is an effective therapy for benign DAVFs, that are not amenable to surgical or endovascular monotherapy. Gamma Knife surgery is less invasive than endovascular treatment and surgery and also offers a high probability of symptomatic and angiographic cures. (41)
Since first case series was reported by BarciaSalorio et al. in 1991, many reports have been debated. Stereotactic radiosurgery is best suited for non hemorrhagic lesions, without CVD and for low-flow cavernous DAVFs (Barrow Types B-D). $(4,18)$ GKS can be a first line of treatment in the multidisciplinary treatment strategy used for DAVFs when significant morbidity is expected to be associated with other therapeutic options. (19)

\section{Case report}

A 59 year old male was brought to the Emergency Department of the National Institute of Neurology and Neurovascular Diseases in a comatose state (GCS $-5 \mathrm{p})$, with ineffective breathing $\left(\mathrm{S}_{\mathrm{p}} \mathrm{O}_{2}\right.$ $86 \%$ ), following a sudden onset of severe headache and vomiting. Based on the patients' neurological state at admission, the suspicion of a posterior fossa hemorrhage was raised and a CT scan was quickly performed (Figure 1), which revealed a brainstem and vermian hematoma with intraventricular hemorrhage $\left(4^{\text {th }}\right.$ ventricle $)$.

Digital substraction angiography was performed, revealing a class IV dural fistula (Cognard classification) from the meningo-pituitary trunk bilaterally, the middle meningeal artery bilaterally and from the left occipital artery. The fistula had a paramedian occipital localization. It drained in the superior sagittal sinus, in the left lateral sinus and in deep veins which had an increased diameter (Figure 2).

Chest X-Ray showed multiple infiltrative opacities bilaterally (Figure 3)

A complete blood count was performed, showing leukocytosis with neutrophilia. The patient also had an increased TnI and high blood glucose levels.

The patient was admitted in the Intensive Care Unit in a comatose state (GCS 5) and an orotracheal intubation was performed. He had purulent tracheobronchial secretions and his APACHE II score was 15 . While in the ICU, the following measures were taken:

- vital functions support: freeing up the airway, mechanical ventilation BIPAP ASB FiO2 = $80 \%$, maintaining a hydroelectrolytic balance and hemodinamic support;

- broad spectrum antibiotics (Tienam 4g/day) and antifungal medication;

- bronchodilators, medication to fluidize the patients bronchial secretions as well tracheobronchial secretions drainage;

- hemostatics; 


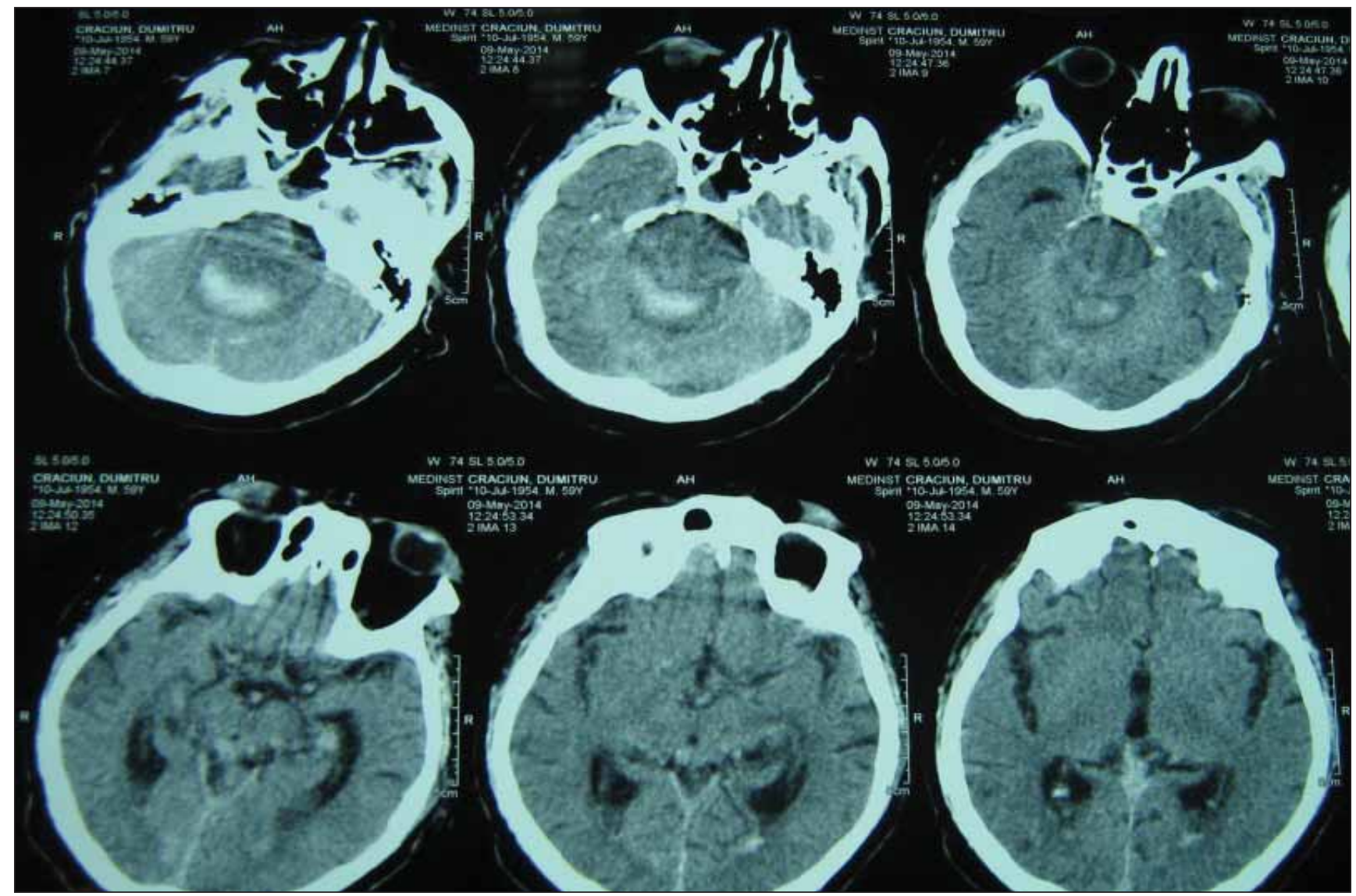

FIGURE 1
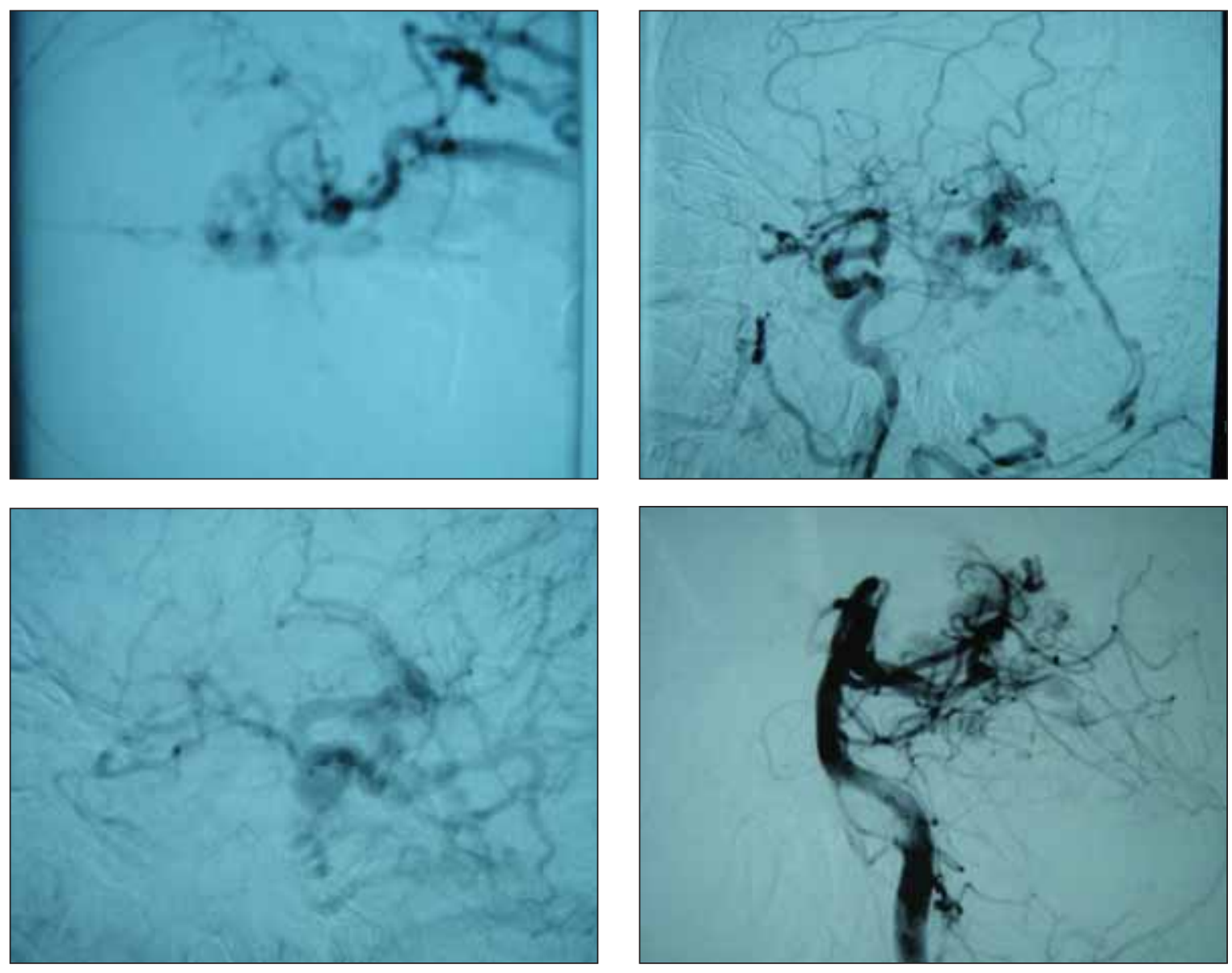


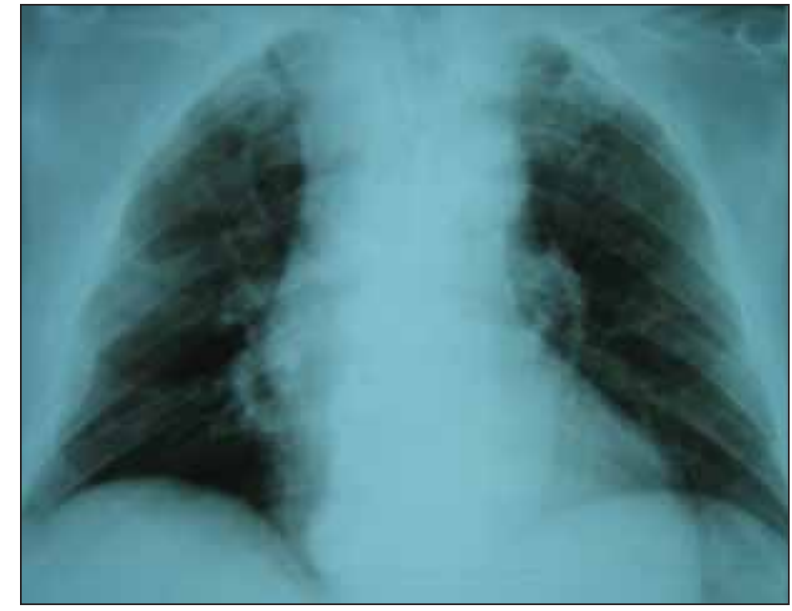

FIGURE 3

- low dose corticosteroids;

- vitamins and neurotropic treatment (for neural regeneration purposes);

- anti-seizure medication;

- cerebral vasodilators (in order to regulate $\mathrm{CBF}$;

\section{REFERENCES}

1. Adamczyk P., Amar A.P., Mack W.J., Larsen D.W. Recurrence of "cured" dural arteriovenous fistulas after Onyx embolization. Neurosurg Focus. 2012; 32(5):E12.

2. Al-Shahi R., Bhattacharya J.J., Currie D.G., Papanastassiou V., Ritchie V., Roberts R.C., et al. Prospective, population-based detection of intracranial vascular malformations in adults: the Scottish Intracranial Vascular Malformation Study (SIVMS). Stroke. 2003; 34(5):1163-9.

3. Bahar S., Chiras J., Carpena J.P., Meder J.F., Bories J. Spontaneous vertebro-vertebral arterio-venous fistula associated with fibro-muscular dysplasia. Report of two cases. Neuroradiology. 1984; 26(1):45-9.

4. Barrow D.L., Spector R.H., Braun I.F., Landman J.A., Tindall S.C., Tindall G.T. Classification and treatment of spontaneous carotid-cavernous sinus fistulas. J Neurosurg. 1985; 62(2):248-56.

5. Borden J.A., Wu J.K., Shucart W.A. Correction: dural arteriovenous fistulous malformations. J Neurosurg. 1995; 82(4):705-6.

6. Borden J.A., Wu J.K., Shucart W.A. A proposed classification for spinal and cranial dural arteriovenous fistulous malformations and implications for treatment. J Neurosurg. 1995;82(2):166-79.

7. Bret P., Salzmann M., Bascoulergue Y., Guyotat J. Dural arteriovenous fistula of the posterior fossa draining into the spinal medullary veins--an unusual cause of myelopathy: case report. Neurosurgery. 1994; 35(5):965-8; discussion 8-9.

8. Brown R.D., Jr., Wiebers D.O., Nichols D.A. Intracranial dural arteriovenous fistulae: angiographic predictors of intracranial hemorrhage and clinical outcome in nonsurgical patients. J Neurosurg. 1994; 81(4):531-8.

9. Cognard C., Gobin Y.P., Pierot L., Bailly A.L., Houdart E., Casasco A., et al. Cerebral dural arteriovenous fistulas: clinical and angiographic correlation with a revised classification of venous drainage. Radiology. 1995; 194(3):671-80.

10. da Costa L.B., Terbrugge K., Farb R., Wallace M.C. Surgical disconnection of cortical venous reflux as a treatment for Borden type II dural arteriovenous fistulae. Acta Neurochir (Wien). 2007; 149(11):1103-8; discussion 8.
- coronarodilator medication, antihypertension medication;

- enteral and parenteral nutrition;

- physiotherapy, neuro-motor recovery and respiratory recovery regimens.

On the $12^{\text {th }}$ day since admission, a tracheostomy was done in order to facilitate tracheobronchial secretions drainage.

The patients clinical evolution was marked by the persistence of leukocytosis and immunosupression with SIRS, which did not evolve to sepsis due to the appropriate medical treatment. The patient had a favorable outcome with a marked neurological recovery, became conscious, oriented and cooperative, his biological profile improved and he developed an effective cough.

Another CT scan, done on day 35 after admission, showed complete blood resorbtion with a normal sized midline ventricular system, without signs of periventricular resorbtion.

11. Daniels D.J., Vellimana A.K., Zipfel G.J., Lanzino G. Intracranial hemorrhage from dural arteriovenous fistulas: clinical features and outcome. Neurosurg Focus. 2013; 34(5):E15.

12. Davies M.A., TerBrugge K., Willinsky R., Coyne T., Saleh J., Wallace M.C. The validity of classification for the clinical presentation of intracranial dural arteriovenous fistulas. J Neurosurg. 1996; 85(5):830-7.

13. Duffau H., Lopes M., Janosevic V., Sichez J.P., Faillot T., Capelle L., et al. Early rebleeding from intracranial dural arteriovenous fistulas: report of 20 cases and review of the literature. J Neurosurg. 1999; 90(1):78-84.

14. Endo S., Kuwayama N., Takaku A., Nishijima M. Direct packing of the isolated sinus in patients with dural arteriovenous fistulas of the transverse-sigmoid sinus. J Neurosurg. 1998; 88(3):449-56.

15. Gelwan M.J., Choi I.S., Berenstein A., Pile-Spellman J.M., Kupersmith M.J. Dural arteriovenous malformations and papilledema. Neurosurgery. 1988; 22(6 Pt 1):1079-84.

16. Goto K., Sidipratomo P., Ogata N., Inoue T., Matsuno H. Combining endovascular and neurosurgical treatments of high-risk dural arteriovenous fistulas in the lateral sinus and the confluence of the sinuses. J Neurosurg. 1999; 90(2):289-99.

17. Grisoli F., Vincentelli F., Fuchs S., Baldini M., Raybaud C., Leclercq T.A., et al. Surgical treatment of tentorial arteriovenous malformations draining into the subarachnoid space. Report of four cases. J Neurosurg. 1984; 60(5):1059-66.

18. Gross B.A., Ropper A.E., Popp A.J., Du R. Stereotactic radiosurgery for cerebral dural arteriovenous fistulas. Neurosurg Focus. 2012; 32(5):E18.

19. Hanakita S., Koga T., Shin M., Shojima M., Igaki H., Saito N. Role of Gamma Knife surgery in the treatment of intracranial dural arteriovenous fistulas. J Neurosurg. 2012; 117 Suppl:158-63.

20. Hoh B.L., Choudhri T.F., Connolly E.S., Jr., Solomon R.A. Surgical management of high-grade intracranial dural arteriovenous fistulas: leptomeningeal venous disruption without nidus excision. Neurosurgery. 1998; 42(4):796-804; discussion -5. 
21. Houdart E., Saint-Maurice J.P., Chapot R., Ditchfield A., Blanquet A., Lot G., et al. Transcranial approach for venous embolization of dural arteriovenous fistulas. J Neurosurg. 2002; 97(2):280-6.

22. Hurst R.W., Bagley L.J., Galetta S., Glosser G., Lieberman A.P., Trojanowski J., et al. Dementia resulting from dural arteriovenous fistulas: the pathologic findings of venous hypertensive encephalopathy. AJNR Am J Neuroradiol. 1998; 19(7):1267-73.

23. Imazeki R., Amari K., Sekiguchi T., Mochizuki T., Shimizu S., Yamamoto M., et al. Rapidly progressive dementia caused by a superior sagittal sinus dural arteriovenous fistula: a case report. Tokai $J$ Exp Clin Med. 2015; 40(1):22-6.

24. Iwama T., Hashimoto N., Takagi Y., Tanaka M., Yamamoto S., Nishi S., et al. Hemodynamic and metabolic disturbances in patients with intracranial dural arteriovenous fistulas: positron emission tomography evaluation before and after treatment. $J$ Neurosurg. 1997; 86(5):806-11.

25. Kanemaru K., Kinouchi H., Yoshioka H., Yagi T., Wakai T., Hashimoto K., et al. Cerebral hemodynamic disturbance in dural arteriovenous fistula with retrograde leptomeningeal venous drainage: a prospective study using I-iodoamphetamine single photon emission computed tomography. J Neurosurg. 2015:1-8.

26. Kulwin C., Bohnstedt B.N., Scott J.A., Cohen-Gadol A. Dural arteriovenous fistulas presenting with brainstem dysfunction: diagnosis and surgical treatment. Neurosurg Focus. 2012; 32(5):E10.

27. Kwon B.J., Han M.H., Kang H.S., Chang K.H. MR imaging findings of intracranial dural arteriovenous fistulas: relations with venous drainage patterns. AJNR Am J Neuroradiol. 2005; 26(10):2500-7.

28. Lagares A., Perez-Nunez A. Alday R., Ramos A., Campollo J., Lobato R.D. Dural arteriovenous fistula presenting as brainstem ischaemia. Acta Neurochir (Wien). 2007;149(9):965-7; discussion 7.

29. Lalwani A.K., Dowd C.F., Halbach V.V. Grading venous restrictive disease in patients with dural arteriovenous fistulas of the transverse/ sigmoid sinus. J Neurosurg. 1993; 79(1):11-5.

30. Lasjaunias P., Chiu M., ter Brugge K., Tolia A., Hurth M., Bernstein M. Neurological manifestations of intracranial dural arteriovenous malformations. J Neurosurg. 1986; 64(5):724-30.

31. Martin N.A., King W.A., Wilson C.B., Nutik S., Carter L.P., Spetzler R.F. Management of dural arteriovenous malformations of the anterior cranial fossa. J Neurosurg. 1990; 72(5):692-7.
32. Miyamoto N., Naito I., Shimizu T., Yoshimoto Y. Efficacy and limitations of transarterial acrylic glue embolization for intracranial dural arteriovenous fistulas. Neurol Med Chir (Tokyo). 2015; 55(2):163-72.

33. Nakamura M., Nakamura Y., Fujita A., Kohmura E. Selective transvenous embolization for dural arteriovenous fistulas with the aid of superselective venograms of fistulous drainages and involved sinuses. Interv Neuroradiol. 2004; 10 Suppl 1:43-50.

34. Quinones-Hinojosa A. Schmidek and Sweet: Operative Neurosurgical Techniques: Indications, Methods and Results (Expert Consult - Online and Print): Elsevier Health Sciences; 2012.

35. Satomi J., van Dijk J.M., Terbrugge K.G., Willinsky R.A., Wallace M.C. Benign cranial dural arteriovenous fistulas: outcome of conservative management based on the natural history of the lesion. J Neurosurg. 2002; 97(4):767-70.

36. Schievink W.I., Piepgras D.G. Cervical vertebral artery aneurysms and arteriovenous fistulae in neurofibromatosis type 1: case reports. Neurosurgery. 1991; 29(5):760-5.

37. Vadivelu S., Xin X., Loven T., Restrepo G., Chalif D.J., Setton A. latrogenic dural arteriovenous fistula and aneurysmal subarachnoid hemorrhage. Neurosurg Focus. 2012;32(5):E1.

38. van Dijk J.M., terBrugge K.G., Willinsky R.A., Wallace M.C. Clinical course of cranial dural arteriovenous fistulas with long-term persistent cortical venous reflux. Stroke. 2002;33(5):1233-6.

39. Wilkins R.H., Rengachary S.S. Neurosurgery: McGraw-Hill; 1995.

40. Willinsky R., TerBrugge K., Lasjaunias P., Montanera W. The variable presentations of craniocervical and cervical dural arteriovenous malformations. Surg Neurol. 1990; 34(2):118-23.

41. Wu H.M., Pan D.H., Chung W.Y., Guo W.Y., Liu K.D., Shiau C.Y., et al. Gamma Knife surgery for the management of intracranial dural arteriovenous fistulas. J Neurosurg. 2006; 105 Suppl:43-51.

42. Zeidman S.M., Monsein L.H., Arosarena O., Aletich V., Biafore J.A., Dawson R.C., et al. Reversibility of white matter changes and dementia after treatment of dural fistulas. AJNR Am J Neuroradiol. 1995; 16(5):1080-3.

43. Zipfel G.J., Shah M.N., Refai D., Dacey R.G., Jr., Derdeyn C.P. Cranial dural arteriovenous fistulas: modification of angiographic classification scales based on new natural history data. Neurosurg Focus. 2009; 26(5):E14. 